Article

\title{
Coordinated Control of HVDC and HVAC Power Transmission Systems Integrating a Large Offshore Wind Farm
}

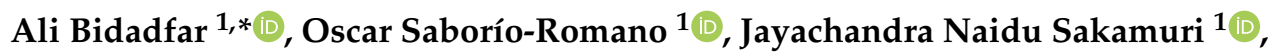 \\ Vladislav Akhmatov ${ }^{2}$, Nicolaos Antonio Cutululis ${ }^{1}$ (D) and Poul Ejnar Sørensen ${ }^{1}$ (D) \\ 1 Department of Wind Energy, Technical University of Denmark, Building 115, Risø Campus, \\ Frederiksborgvej 399, 4000 Roskilde, Denmark \\ 2 Energinet, Tonne Kjærsvej 65, 7000 Fredericia, Denmark \\ * Correspondence: abid@dtu.dk
}

Received: 5 August 2019; Accepted: 3 September 2019; Published: 6 September 2019

\begin{abstract}
The development of efficient and reliable offshore electrical transmission infrastructure is a key factor in the proliferation of offshore wind farms (OWFs). Traditionally, high-voltage AC (HVAC) transmission has been used for OWFs. Recently, voltage-source-converter-based (VSC-based) high-voltage DC (VSC-HVDC) transmission technologies have also been considered due to their grid-forming capabilities. Diode-rectifier-based (DR-based) HVDC (DR-HVDC) transmission is also getting attention due to its increased reliability and reduced offshore platform footprint. Parallel operation of transmission systems using such technologies can be expected in the near future as new OWFs are planned in the vicinity of existing ones, with connections to more than one onshore AC system. This work addresses the control and parallel operation of three transmission links: VSC-HVDC, DR-HVDC, and HVAC, connecting a large OWF (cluster) to three different onshore AC systems. The HVAC link forms the offshore AC grid, while the diode rectifier and the wind farm are synchronized to this grid voltage. The offshore HVDC converter can operate in grid-following or grid-forming mode, depending on the requirement. The contributions of this paper are threefold. (1) Novel DR- and VSC-HVDC control methods are proposed for the parallel operation of the three transmission systems. (2) An effective control method for the offshore converter of VSC-HVDC is proposed such that it can effectively operate as either a grid-following or a grid-forming converter. (3) A novel phase-locked loop (PLL) control for VSC-HVDC is proposed for the easy transition from the grid-following to the grid-forming converter in case the HVAC link trips. Dynamic simulations in PSCAD validate the ability of the proposed controllers to ride through faults and transition between grid-following and grid-forming operation.
\end{abstract}

Keywords: offshore wind; power transmission systems; diode rectifiers; converter control system; HVDC links

\section{Introduction}

Offshore wind is known as a reliable source of energy. Compared to onshore wind, it has higher full-load hours and more constant power generation capacity across the year. The European Union has the ambition of achieving $40 \mathrm{GW}$ of offshore generation by the end of 2020. More reliable and cost benefit power transmission systems are the key players for further development of offshore wind [1]. To date, high voltage AC (HVAC) is predominantly used in the transmission of offshore wind power [2]. However, the applicability of HVAC is limited to the offshore wind farms (OWFs) that are relatively close to the shore (less than around $80 \mathrm{~km}$, if the line is not compensated in the middle). High voltage DC (HVDC) technology is more cost-effective for remote OWFs and has been mainly 
based on voltage source converters (VSCs), which provide advantages such as smaller footprints and grid-forming capability. The latter implies that the offshore HVDC terminal can generate (form) the AC voltage for the corresponding offshore AC network, which makes it possible to use the prevailing (grid-following) approach to controlling wind turbines.

Recently, diode rectifiers (DRs) have been proposed as an alternative for connecting OWFs to HVDC [3-8]. DR-HVDC transmission systems offer advantages such as smaller footprints, lower costs, higher efficiency, and higher reliability $[5,7,9]$. However, due to their lack of grid-forming capabilities, their use requires delegating such responsibility to, e.g., the wind turbines (WTs) [10] or their parallel operation with VSC-HVDC and/or HVAC links, which take the responsibility of forming the offshore AC network.

To increase the reliability of offshore generation and transmission, the neighboring OWFs can be interconnected via AC links. As a result, offshore AC networks (called energy hubs) can emerge [11]. An offshore AC network, including a few OWFs, can transmit power to more than one onshore power system via different power transmission technologies. In [1], control and operation of multiple HVDC links, together connecting a large offshore AC network to different onshore systems, were investigated. Hybrid offshore connections using DR- and VSC-HVDC links were investigated in [12-14]. In these references, the application of DR-HVDC was still based on the grid-forming capability of wind turbine converters, which, to date, is under research investigation. Moreover, the power flow through the DR-HVDC, in a hybrid application, relies on the offshore AC voltage magnitude, which is controlled by the wind turbines. This means that the operators of the OWF and HVDC links should cooperate for controlling the power flow through the transmission links, which imposes a burden on the operators. This control scheme has two problems: the first one is that offshore reactive power balance and DR-HVDC active power interact with each other as both depend on the AC voltage magnitude, and it is not straightforward to optimize the offshore reactive power under different and varying OWF active power generation. The second is that a continuous communication is needed between DR-HVDC and OWF to regulate the power flow through the DR connection.

In this paper, the simultaneous use of three different power transmission links integrating a large OWF is investigated. It is assumed that an OWF, as shown in Figure 1, delivers the power to different onshore AC systems via HVAC, VSC-HVDC, and DR-HVDC transmission links. Control systems for VSCs are proposed such that the power flow through each link is controlled. Since the operation of the WTs and the DR-HVDC link rely on the AC grid that either the HVAC or the VSC-HVDC links provide, the control of the only offshore VSC (in the VSC-HVDC link) is significantly important. If the HVAC link is disconnected, the VSC-HVDC link must immediately and without interruption take over the grid-forming responsibility. A novel control scheme is proposed for the VSC-HVDC link. In such a scheme, the offshore VSC operates in grid-following mode when the HVAC link is connected and switches seamlessly to grid-forming mode when the HVAC trips by detecting the offshore frequency deviation. Moreover, a new power flow control method is proposed for DR-HVDC. In such a method, a proportional-integral (PI) regulator in an outer loop controls the power flow through such a link by manipulating its onshore HVDC terminal voltage. The proposed DR-HVDC power control makes the DR operation independent of OWF control, which is a solution for the problem mentioned above regarding DR operation in a hybrid connection.

The rest of the paper is organized as follows. The investigated system is described in Section 2. The proposed control schemes are presented in Section 3. In Section 4, the considered scenarios are described and corresponding simulation results are presented and discussed. Finally, concluding remarks are made in Section 5. 


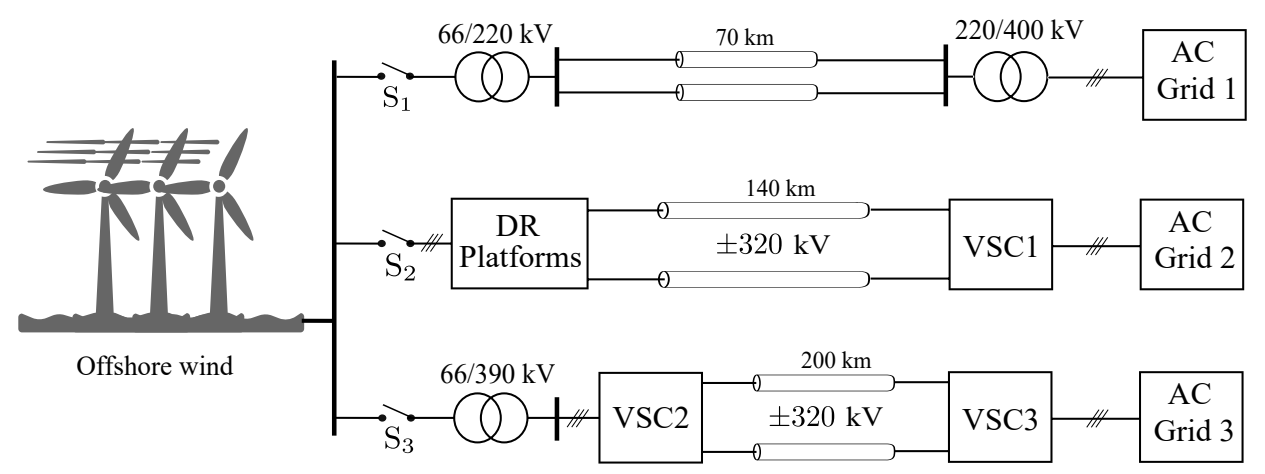

Figure 1. Overview of the studied system. VSC, voltage-source-converter.

\section{Model Description and Operation}

The studied system, shown in Figure 1, includes an HVAC, a VSC-HVDC, and a DR-HVDC transmission link, connecting a large OWF with three different onshore AC systems. An offshore supervisory control is assumed to distribute the power generated by the OWF over the transmission links. Each HVDC link can control its power flow to follow the dispatch from the supervisory control, and the rest of the OWF output power is exported through the HVAC link as a result.

The system has a total of three HVDC VSCs (in the HVDC links), which control the overall power flow and HVDC link voltages. Such converters are assumed to be modular multilevel converters (MMCs) and are represented by the generic models proposed in [15].

The DR-HVDC offshore terminal in Figure 1 consists of three DR platforms connected in series. Each DR platform consists of two (uncontrolled, line-commutated) diode-based 12-pulse rectifiers connected in series, with the corresponding reactive power compensation and filter bank on their AC side.

The offshore wind farm is modeled as aggregated IECfull-converter (Type-4) wind turbines (WTs) based on the aggregation method given in [16]. Each WT grid-side converter operates in gridfollowing mode and uses conventional vector current control [17]. As described by (1), WT reactive and active power outputs are regulated by means of outer loops with proportional controllers (droops) acting on the errors in AC terminal voltage (magnitude) and frequency, respectively, where $k_{\mathrm{wt}}^{\mathrm{V}}$ and $k_{\mathrm{wt}}^{\mathrm{f}}$ are the corresponding proportional gains. $P_{\mathrm{wt}}^{0}, Q_{\mathrm{wt}}^{0}, V_{\mathrm{AC}}^{\text {ref }}$, and $f_{0}$ are determined by the offshore supervisory control.

$$
Q_{\mathrm{wt}}^{\mathrm{ref}}=Q_{\mathrm{wt}}^{0}-k_{\mathrm{wt}}^{\mathrm{V}}\left(V_{\mathrm{AC}}-V_{\mathrm{AC}}^{\mathrm{ref}}\right), \quad P_{\mathrm{wt}}^{\mathrm{ref}}=P_{\mathrm{wt}}^{0}-k_{\mathrm{wt}}^{\mathrm{f}}\left(f-f_{0}\right)
$$

\section{Control Systems}

The control schemes of the three HVDC VSCs in the studied system are discussed in this section. VSC1 controls the power flow in the DR-HVDC link by manipulating its DC terminal voltage according to the proposed cascaded control scheme shown in Figure 2. Although the DC-link voltage is influenced by the offshore alternating voltage, due to the diode rectifiers characteristics, including the DC-link voltage control in the proposed control scheme, shown in Figure 2, can limit the voltage deviations.

VSC2 and VSC3 control the power flow and voltage, respectively, in the VSC-HVDC link. Two objectives are considered when controlling VSC2. Firstly, it should operate in grid-following mode when the HVAC link is connected and in grid-forming mode if such a link is disconnected. Secondly, it should control active and reactive power independently when operating in grid-following mode, even if the offshore AC grid is weak. Conventional controls are not applicable for VSC2, as they cannot seamlessly switch between grid-following and grid-forming modes.

New phase-locked loop (PLL) and converter control approaches are proposed for VSC2. The model of the proposed PLL is shown in Figure 3. The control blocks shown inside the dashed rectangle are added to a conventional PLL. In the case of HVAC outage, the offshore frequency drifts 
and goes beyond the deadband limits. The proportional feedback loop with the gain $k_{\mathrm{p}}$ resists against a high-frequency change. The switch $\mathrm{S}_{\mathrm{f}}$ is closed by offshore supervisory control when the HVAC outage is detected. The integrator with the gain $k_{\mathrm{i}}$ then forces the frequency deviation, $\Delta f$, to return to zero. Therefore, the PLL generates a reference signal, $\theta_{\mathrm{u}}$, with a constant frequency, $f_{0}$, and no longer follows the grid, instead forming an AC grid. In this case, when the converter switches from grid-forming to grid-following, the switch $\mathrm{S}_{\mathrm{f}}$ is opened, and the integrator is reset to zero.

The proposed control scheme for VSC2, shown in Figure 4, is a PLL-based power-angle control $[18,19]$, which uses the inner current control loops (current reference control and current controller in Figure 4), proposed in power-synchronization control [20,21]. In the proposed controls, VSC2's active power output is controlled by the converter's voltage angle. VSC2's filter bus alternating voltage is controlled by the converter's voltage magnitude. The converter's current components (in the rotating reference frame) are controlled in the same way as in power-synchronization control, but a PLL is used to generate the transformation angle, $\theta_{\mathrm{u}}$, i.e., synchronize with the offshore AC grid.

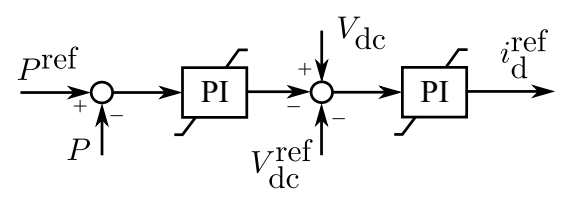

Figure 2. Diode-rectifier (DR)-HVDC link power and voltage controls used in VSC1.

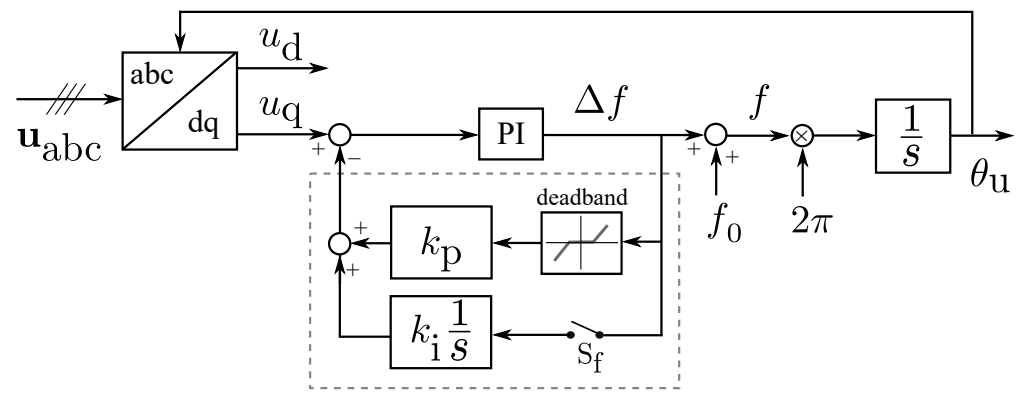

Figure 3. Proposed PLL model used in VSC2.

In the control block diagram shown in Figure $4, \mathbf{u}_{\mathrm{f}}$ is the VSC2 filter bus voltage (complex space) vector, with magnitude $U$. The initial references for the converter AC terminal voltage vector magnitude, $V_{0}$, and angle, $\phi_{0}$, are generated by two proportional-integral (PI) regulators, which control $U$ and the active power output $P$, respectively. Such a vector, $\mathbf{v}_{0}$, is then expressed in rectangular form.

Besides power and voltage, the converter current must also be controlled to limit the fault current and remove high-frequency resonances from the current. The current vector reference, $\mathbf{i}_{\mathrm{c}}^{\text {ref }}$, is generated using the voltage reference vector $\mathbf{v}_{0}$. To do so, the technique proposed in [20] is used as:

$$
\mathbf{i}_{\mathrm{c}}^{\text {ref }}=\mathbf{i}_{\mathrm{c}}+\frac{1}{\alpha_{\mathrm{c}} L_{\mathrm{c}}}\left[\mathbf{v}_{0}-H_{\mathrm{HP}}(s) \mathbf{i}_{\mathrm{c}}-H_{\mathrm{LP}}(s) \mathbf{u}_{\mathrm{f}}-\mathrm{j} \omega L_{\mathrm{c}} \mathbf{i}_{\mathrm{c}}\right]
$$

where $\alpha_{\mathrm{c}}$ is the desired closed-loop bandwidth of the current controller. The functions $H_{\mathrm{LP}}(s)$ and $H_{\mathrm{HP}}(s)$ are respectively low- and high-pass filters with the following expressions:

$$
H_{\mathrm{LP}}(s)=\frac{\alpha_{\mathrm{f}}}{s+\alpha_{\mathrm{f}}} \quad, \quad H_{\mathrm{HP}}(s)=\frac{k_{\mathrm{v}} s}{s+\alpha_{\mathrm{v}}}
$$

where the bandwidth $\alpha_{\mathrm{f}}$ is typically in the range of $[40,100] \mathrm{rad} / \mathrm{s}$, and the bandwidth $\alpha_{\mathrm{v}}$ is chosen low enough to cover all the possible resonances in the AC system, typically in the range of [30,50] rad / s [20]. The gain $k_{\mathrm{v}}$ determines the level of damping and is chosen in the range of $[0.2,0.6] \mathrm{pu}$. 
The current controller block in Figure 4 uses the reference current, $i_{\mathrm{c}}^{\text {ref }}$, to generate the converter's reference voltage by the following inner-current control approach:

$$
\mathbf{v}_{\mathrm{dq}}^{\mathrm{ref}}=\alpha_{\mathrm{c}} L_{\mathrm{c}}\left(\mathbf{i}_{\mathrm{c}}^{\mathrm{ref}}-\mathbf{i}_{\mathrm{c}}\right)+\mathrm{j} \omega L_{\mathrm{c}} \mathbf{i}_{\mathrm{c}}+H_{\mathrm{LP}}(s) \mathbf{u}_{\mathrm{f}}
$$

Substituting Equation (2) into Equation (4), the voltage-vector control law [20] can be observed as:

$$
\mathbf{v}_{\mathrm{dq}}^{\mathrm{ref}}=\mathbf{v}_{0}-H_{\mathrm{HP}}(s) \mathbf{i}_{\mathrm{c}}
$$

which shows how high-frequency resonances can be filtered out by the controller. Moreover, there is a current limiter inside the current reference control block to limit the fault current.

During the transition from grid-following to grid-forming, $\phi_{0}$ reaches one of the power controller's limits. The controller is thus overridden, and the converter operates as a slack bus, producing a voltage with a fixed frequency.

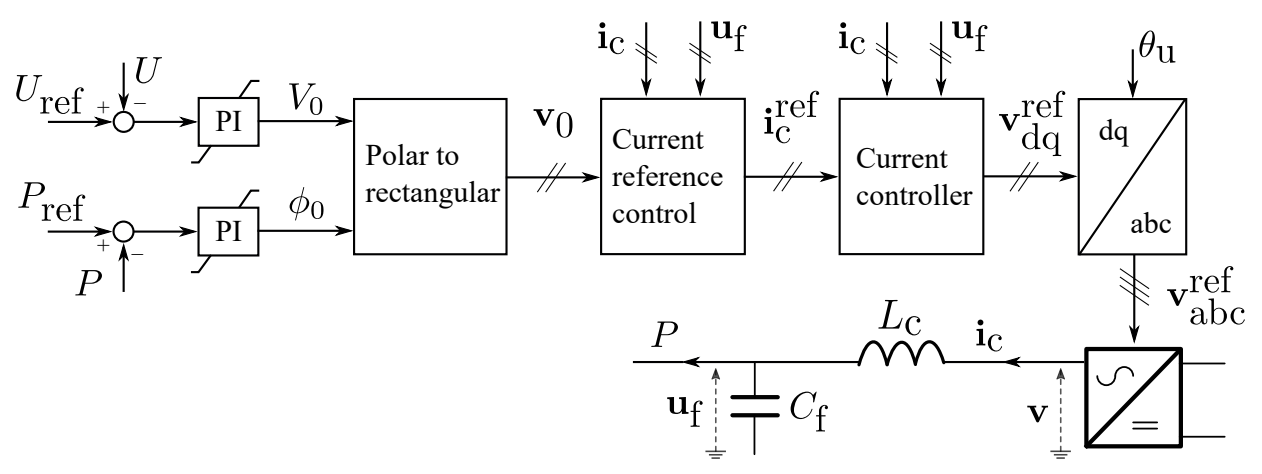

Figure 4. Proposed control scheme used in VSC2.

\section{Simulation Studies}

In this section, the considered scenarios are described and the corresponding results of the dynamic simulations performed in PSCAD are presented and discussed. A simulation time step of $30 \mu \mathrm{s}$ was used. First-order low-pass filters with a time constant of $0.01 \mathrm{~s}$ were applied to the presented active and reactive power responses. The power transmission cables were modeled with the $\pi$ model with the lumped parameters given in Table 1 . This table also presents the parameters of the power and voltage control loops of OWF and HVDC converters.

It is assumed that OWF can produce $2000 \mathrm{MW}$. The HVAC transfers $450 \mathrm{MW}$, DR-HVDC $800 \mathrm{MW}$, and VSC-HVDC $750 \mathrm{MW}$ when the OWF generates its nominal power. 


\subsection{Transition from Grid-Following to Grid-Forming}

Table 1. Cables specifications and control parameters. OWF, offshore wind farm.

\begin{tabular}{|c|c|c|c|}
\hline \multirow[t]{2}{*}{ HVAC } & AC Cables & $\begin{array}{l}\mathrm{R} \\
\mathrm{L} \\
\mathrm{C}\end{array}$ & $\begin{array}{l}0.0351 \Omega / \mathrm{m} \\
0.159 \mathrm{mH} / \mathrm{m} \\
0.182 \mathrm{uF} / \mathrm{m}\end{array}$ \\
\hline & Transformers & $\begin{array}{l}\text { Series Impedance } \\
\text { Nominal power }\end{array}$ & $\begin{array}{l}12 \% \\
550 \mathrm{MVA}\end{array}$ \\
\hline \multirow{3}{*}{ DR-HVDC } & DC Cables & $\begin{array}{l}\mathrm{R} \\
\mathrm{L} \\
\mathrm{C}\end{array}$ & $\begin{array}{l}0.015 \Omega / \mathrm{m} \\
0.156 \mathrm{mH} / \mathrm{m} \\
0.34 \mathrm{uF} / \mathrm{m}\end{array}$ \\
\hline & VSC1 Control & $\begin{array}{l}\text { DC Voltage } \\
\text { Reactive Power }\end{array}$ & $\begin{array}{l}k_{p}=0.5, k_{i}=0.3 \\
k_{p}=0.8, k_{i}=0.1\end{array}$ \\
\hline & Transformers & $\begin{array}{l}\text { Series Impedance } \\
\text { Nominal Power }\end{array}$ & $\begin{array}{l}\text { Onshore: } 12.5 \% \text {, Offshore: } 12.5 \% \\
1000 \text { MVA }\end{array}$ \\
\hline \multirow{4}{*}{ VSC-HVDC } & DC Cables & $\begin{array}{l}\mathrm{R} \\
\mathrm{L} \\
\mathrm{C}\end{array}$ & $\begin{array}{l}0.015 \Omega / \mathrm{m} \\
0.156 \mathrm{mH} / \mathrm{m} \\
0.34 \mathrm{uF} / \mathrm{m}\end{array}$ \\
\hline & VSC2 Control & $\begin{array}{l}\text { Active Power } \\
\text { AC Voltage }\end{array}$ & $\begin{array}{l}k_{p}=0.7, k_{i}=0.1 \\
k_{p}=0.5, k_{i}=0.07\end{array}$ \\
\hline & VSC3 Control & $\begin{array}{l}\text { DC Voltage } \\
\text { Reactive Power }\end{array}$ & $\begin{array}{l}k_{p}=0.8, k_{i}=0.1 \\
k_{p}=0.8, k_{i}=0.1\end{array}$ \\
\hline & Transformers & $\begin{array}{l}\text { Series Impedance } \\
\text { Nominal power }\end{array}$ & $\begin{array}{l}\text { Onshore: } 13 \% \text {, Offshore: } 13 \% \\
1200 \text { MVA }\end{array}$ \\
\hline OWF & Control & $\begin{array}{l}\text { Active Power } \\
\text { Reactive Power } \\
\text { Droops }\end{array}$ & $\begin{array}{l}k_{p}=1, k_{i}=0.05 \\
k_{p}=0.35, k_{i}=0.03 \\
k_{\mathrm{wt}}^{\mathrm{f}}=0.02, k_{\mathrm{wt}}^{\mathrm{V}}=0.05\end{array}$ \\
\hline
\end{tabular}

In the first simulation scenario, it was assumed that the HVAC link trips and the VSC-HVDC takes the responsibility of maintaining the offshore frequency, forming the offshore AC grid. The results for this scenario are shown in Figures 5-8.

As shown in Figure 5, active and reactive power, previously flown through the HVAC, were taken over by the VSC-HVDC after the transition. It was assumed that the VSC-HVDC had a nominal capacity of 1400 MVA; therefore, it could transfer the additional power after the HVAC outage. The voltage of the offshore common coupling point (PCC) and root mean squared (RMS) values of the currents of the OWF, as well as the transmission links are shown in Figure 6. The voltage rose slightly at the beginning of the transition due to the presence of capacitors in the diode rectifier station. Moreover, there was an interaction between the controllers of the VSC2 and WT converters, which resulted in a reactive power spark; however, under the converters current limit. Figure 5 shows the active and reactive power of OWF and transmission systems, when the HVAC trips and VSC2 undergoes a transition from grid-following to grid-forming operation.

The offshore frequency before and after transition is shown in Figure 7. The frequency was measured using the PLL model given in Figure 3. Immediately after the transition, the frequency jumped up due to the independent control of active power and alternating voltage in VSC2. The feedback loop in the PLL with gain $k_{\mathrm{p}}$ restrained the jump. The switch of the integral feedback, $\mathrm{S}_{\mathrm{f}}$ was closed after $100 \mathrm{~ms}$ of HVAC link outage and brought the frequency back to its nominal value as shown in Figure 7. The VSC2 current in the dq frame is also shown in Figure 7. Since the controller was in the grid-forming mode after the transition and the synchronous frame did not follow the VSC2's filter bus, the dq currents lost their patterns from the pre-transition period and no longer resembled the active and reactive power patterns. The initial references of VSC2's voltage angle and magnitude 
are shown in Figure 8. The voltage angle fell to the lower limit of the PI controller and was fixed there during the entire time when VSC2 operated as grid-forming. This implies that the power control loop was not effective anymore. However, as shown in Figure 8, the voltage controller that generated the initial reference for the converter, experienced a short-time transient, almost $200 \mathrm{~ms}$, recovered the offshore AC voltage and maintained it during the post-transition period.
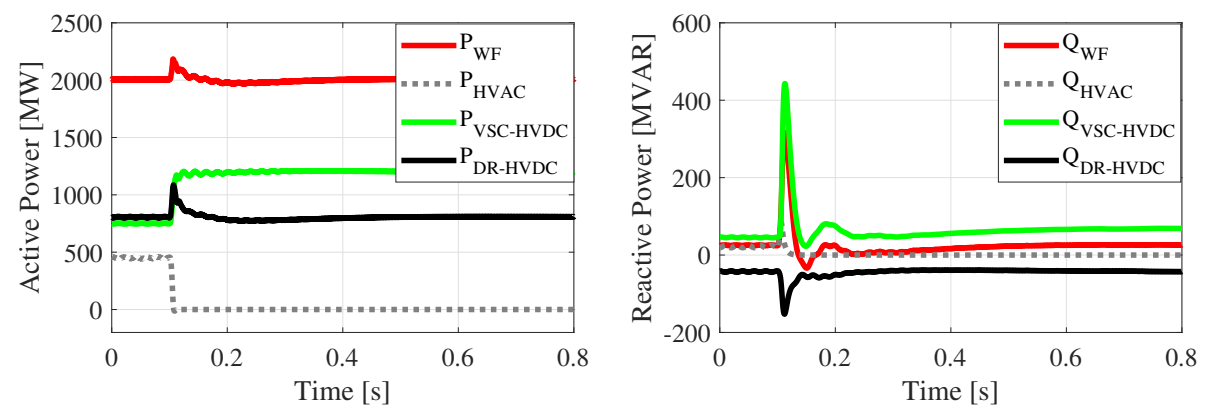

Figure 5. Active (left) and reactive (right) power of OWF and transmission lines when the HVAC link trips.
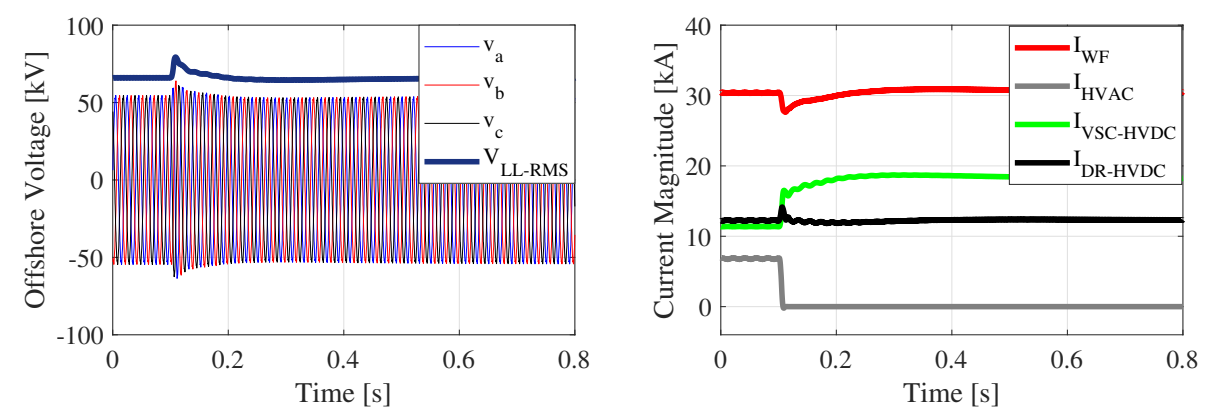

Figure 6. The voltage of offshore common coupling point (PCC) (left) and currents (right) of OWF and transmission lines when the HVAC link trips.
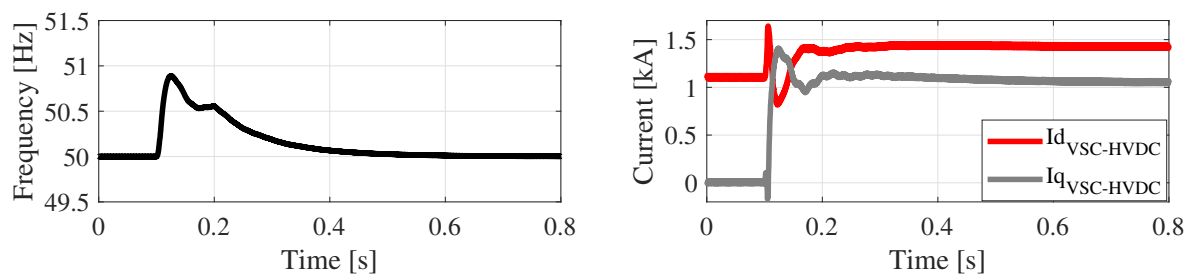

Figure 7. Offshore frequency (left) and currents (right) of VSC2 in the dq synchronous frame.
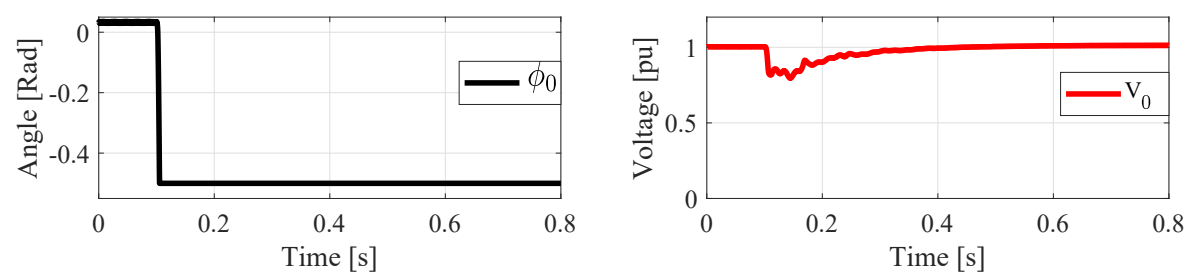

Figure 8. Reference voltage angle (left) and voltage magnitude (right) generated by the proposed controller for VSC2.

\subsection{Transition from Grid-Forming to Grid-Following}

For different reasons such as fault or maintenance, the HVAC link might be disconnected from the offshore network, and VSC2 operates as grid-forming. The situation where the HVAC link is re-connected is simulated in this section to investigate the transition of the proposed controller from 
grid-forming to grid-following. Figures 9-11 show the simulation results for the re-connection of the HVAC link. It is obvious that only VSC2 played a role in the transition and balanced the power-flow between transmission links, which was the main goal of the proposed control scheme. The offshore AC-link voltage in Figure 10 shows the smoothness of the transition.
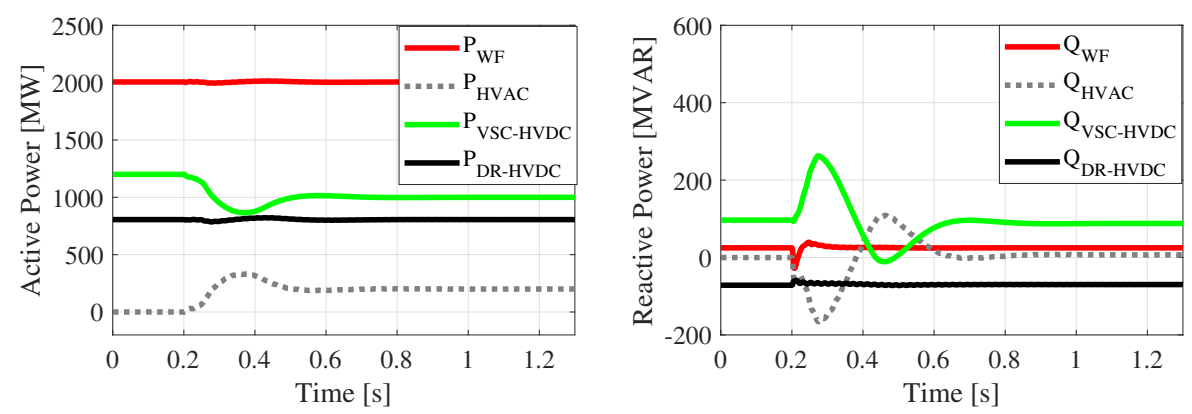

Figure 9. Active (left) and reactive (right) power of OWF and transmission lines when the HVAC link re-connects.
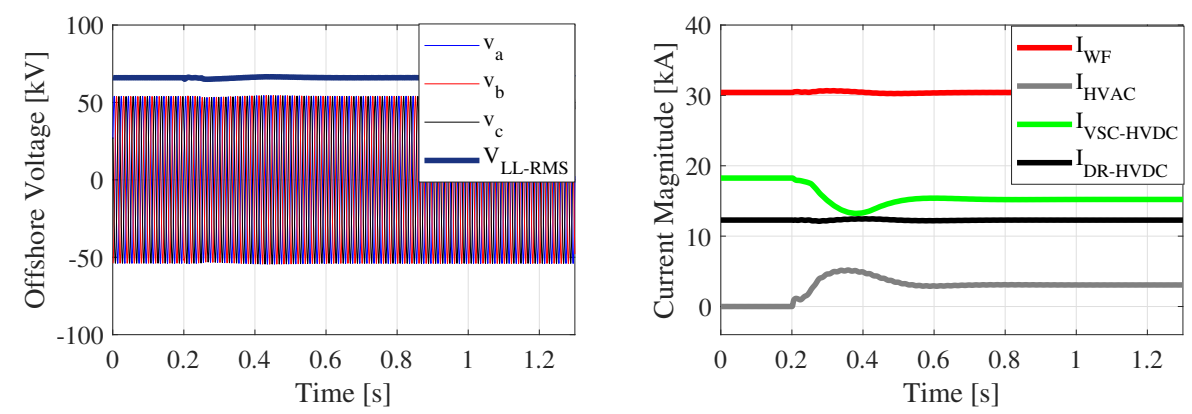

Figure 10. The voltage of offshore PCC (left) and currents (right) of OWF and transmission lines when the HVAC link re-connects.
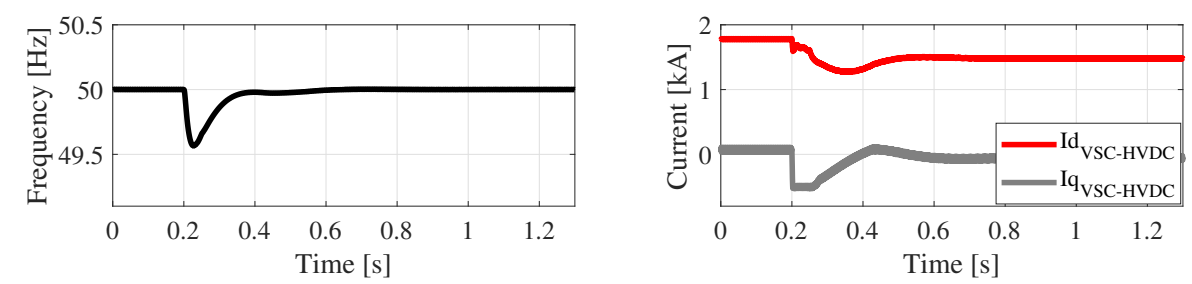

Figure 11. Offshore frequency (left) and currents (right) of VSC2 in the dq synchronous frame when the HVAC link re-connects.

\subsection{Short-Circuit on Offshore PCC}

To investigate the fault current-limiting capability of the proposed control system for VSC2, a three-phase short-circuit was applied to the offshore PCC for $100 \mathrm{~ms}$. Figure 12 shows the offshore PCC voltage and RMS currents of OWF and transmission links. The AC-side current of DR-HVDC became zero since the diode rectifiers did not reverse the current, and hence, no current flowed to the short-circuited point. The OWF's current was controlled through the WT converters, and its magnitude was limited under the fault. The current of the VSC-HVDC was also limited, which showed the fault current-limiting capability of the proposed controller. As shown in Figure 12, it was only the HVAC current that was not limited during the fault, which is almost the case in any AC system without fault current limiters. Active and reactive powers for this scenario are shown in Figure 13. The recovery capability of the proposed controllers for VSC1 and VSC2 is evident from this figure. There was a transient interaction between OWF and VSC2 immediately after the fault clearance, which resulted 
in the reactive power interchange between the two. The system reached the steady-state in less than $100 \mathrm{~ms}$. This indicated an acceptable capability of the proposed controllers to limit the fault current.

A comprehensive stability analysis of an offshore wind farm required more detailed models of wind turbines and their controls, cable arrays, wind farm supervisory control, and so on. However, since an aggregated representation of the offshore wind farm as a single equivalent wind turbine was used in this paper, the scope of the wind farm's stability analysis was limited to whether it can stay connected to the grid under severe fault conditions (e.g., 100-ms three-phase short-circuit), prioritize the control of active or reactive power (or AC voltage) during the fault (in compliance with corresponding grid code requirements), and recover to normal operation immediately after the fault is cleared. The proposed coordinated control of the three different transmission links did not affect the operation and control of the offshore wind farm significantly. Moreover, the proposed control enabled a seamless transition of the offshore AC network from AC-connected operation to AC-disconnected operation (DC-connected only), without imposing any restrictions on or changes in the control and operation of the offshore wind farm. Therefore, the proposed control did not impact the stability of the offshore wind farm. However, key wind farm variables such as voltage, current, and control signals are presented in the simulation results to confirm the stable wind farm operation under severe fault conditions.
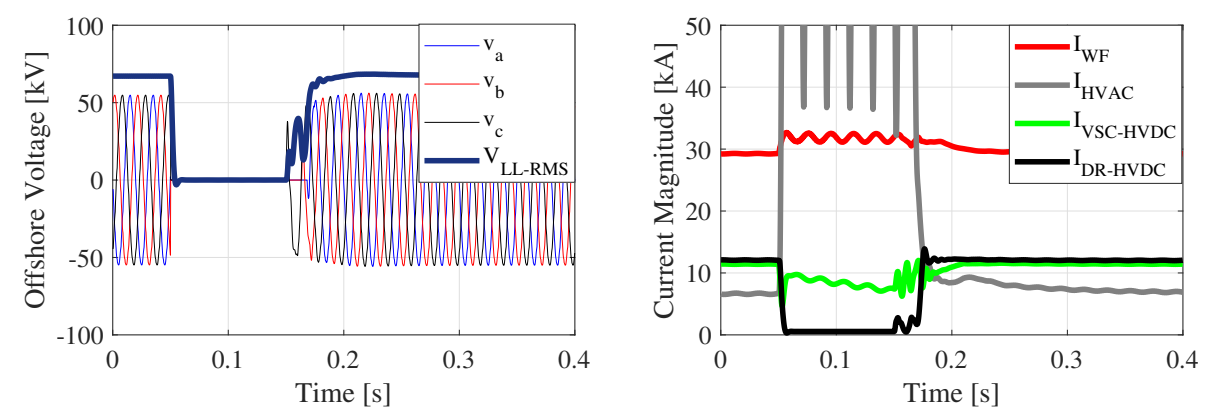

Figure 12. The voltage of offshore PCC (left) and currents (right) of OWF and transmission lines when a three-phase short-circuit occurs in offshore PCC.
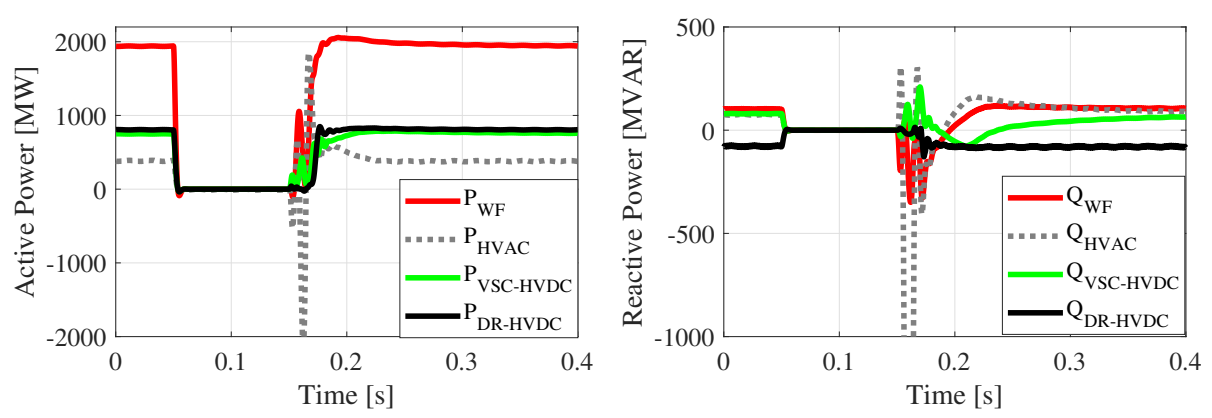

Figure 13. Active (left) and reactive (right) power of OWF and transmission lines when a three-phase short-circuit occurs in offshore PCC.

\subsection{Single-Phase Short Circuit on HVAC Link}

Anther fault scenario was considered as a single-phase short-circuit on the high voltage side of the HVAC link. The results for this scenario are presented in Figures 14-16. After detecting the fault, the HVAC link tripped and reconnected again when the fault was cleared. This means that for a short time, VSC2 operated as grid-forming under faulty conditions and experienced two transitions in a very short time. Since the fault was asymmetric and AC voltage on the offshore side dropped in one phase and rose in two others, the immediate active power rise occurred in DR-HVDC. However, the VSC-HVDC tried to increase its power to establish the balance between generated power by OWF 
and the exported power by the links. Figure 16 shows that offshore frequency and VSC2 currents were all under permitted limits.
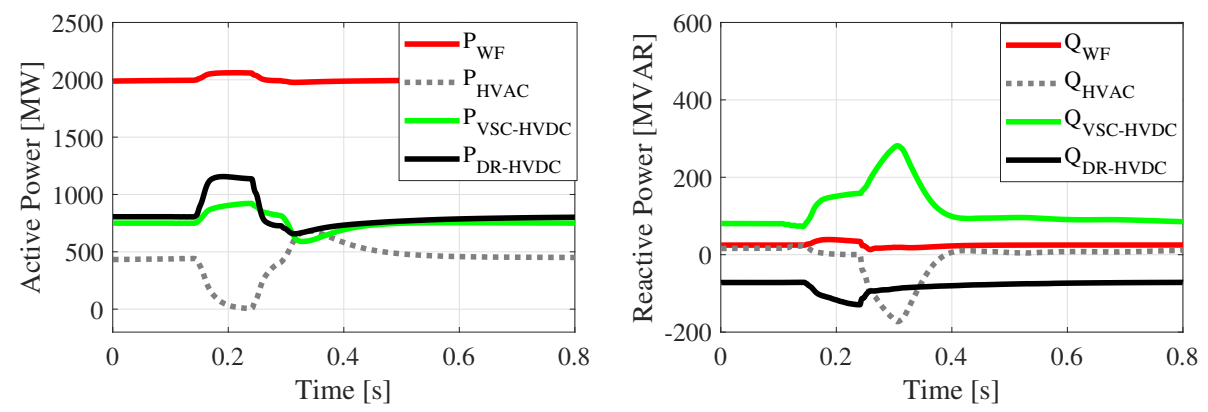

Figure 14. Active (left) and reactive (right) power of OWF and transmission lines when a single-phase fault occurs in the HVAC link.
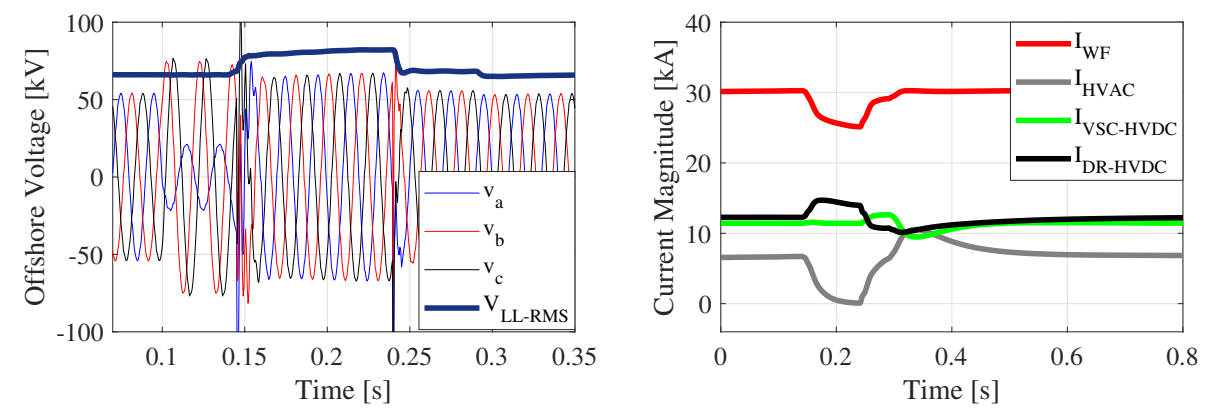

Figure 15. The voltage of offshore PCC (left) and currents (right) of OWF and transmission lines when a single-phase fault occurs in the HVAC link.
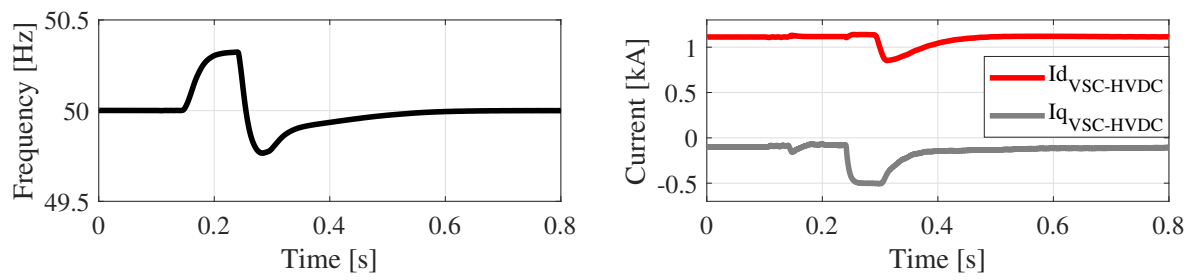

Figure 16. Offshore frequency (left) and currents (right) of VSC2 in the dq synchronous frame when a single-phase fault occurs in the HVAC link.

\subsection{Weak AC Link Interconnection}

To evaluate the capability of the proposed controller for VSC2, in the case that the AC connection was weaker (low short-circuit ratio), it was assumed that one of the cables of the HVAC link tripped and the offshore AC grid became weaker. Figure 17 shows the active and reactive power of OWF and the transmission links of this scenario. After the cable outage, the VSC-HVDC immediately responded to the active and reactive power change of the HVAC link. In fact, the VSC2 took the responsibility of maintaining the continuous operation of OWF and DR-HVDC. However, since the remaining cable of the HVAC link can transfer the 450-MW power, the VSC2 returned the active power to its reference value after a transient. Figure 18 shows the initial voltage reference and currents of the VSC2. The voltage reference was increased to generate more reactive power to compensate for the HVAC reactive power. 

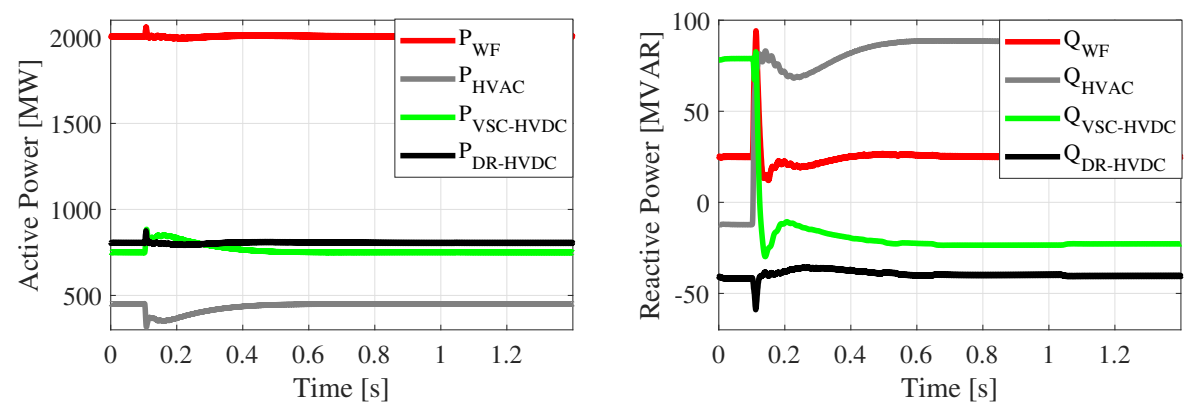

Figure 17. Active (left) and reactive (right) power of OWF and transmission lines when the offshore AC grid became weaker.
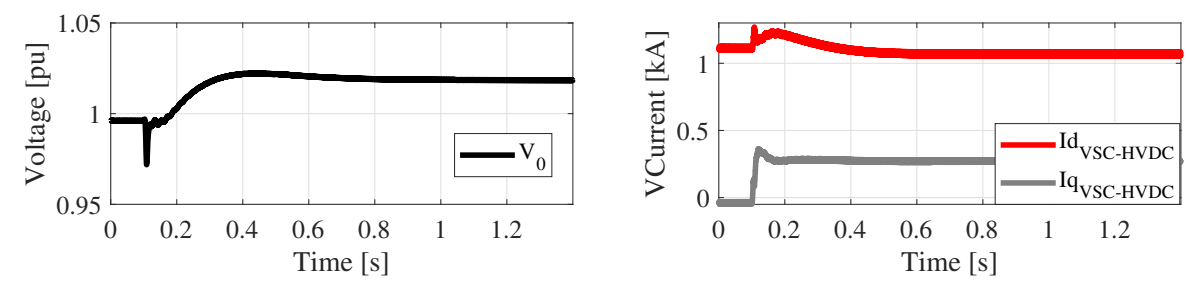

Figure 18. Initial reference of VSC2 voltage (left) and VSC2 currents (right) when the offshore AC grid becomes weaker.

\subsection{DR-HVDC Link Power Ramp-Up}

To evaluate the performance of VSC-HVDC control against a significant change in the DR-HVDC's operation, it was assumed that at the beginning, the DR-HVDC was not conducting and transferred no power. The active power setpoint of the VSC-HVDC was $1000 \mathrm{MW}$ in this scenario. The DR-HVDC started exporting power with a ramp rate of $2000 \mathrm{MW} / \mathrm{s}$. As shown in Figure 19, the active power of VSC-HVDC and OWF was constant during the time when the DR-HVDC started exporting power. Since the filters and reactive power compensators of the DR-HVDC were connected even before its active power conduction, they impacted the entire reactive power dispatch of the transmission lines on the offshore side. However, the VSC2 could counteract with DR-HVDC reactive power change by controlling the offshore AC voltage. The three-phase alternating voltage waveforms of offshore PCC are shown in Figure 20. Since the diode rectifiers created harmonic distortions on the AC voltage, when conducting, it was observed that the alternating voltage waveforms were not as smooth as they were before DRs' conduction. The filters on the DRs' station, however, limited the harmonic distortions to an acceptable level.
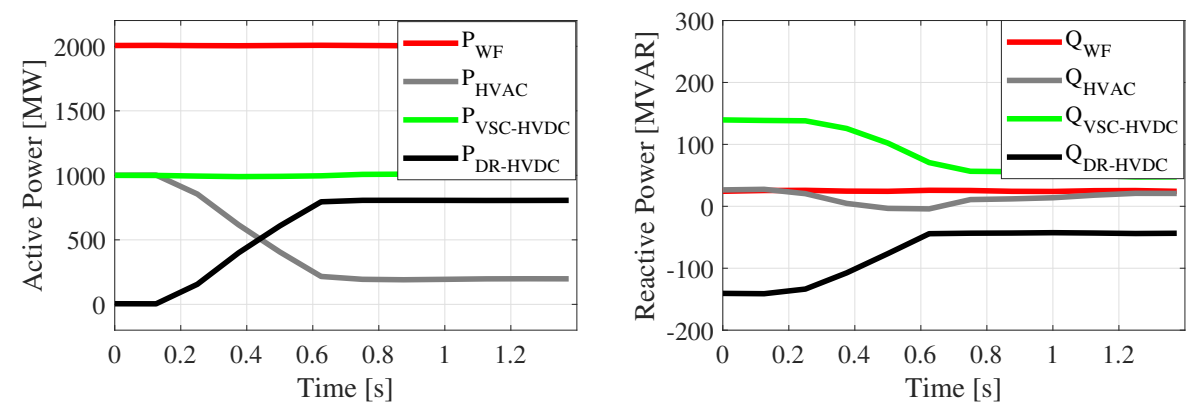

Figure 19. Active (left) and reactive (right) power of OWF and transmission systems during the power ramp-up of DR-HVDC. 

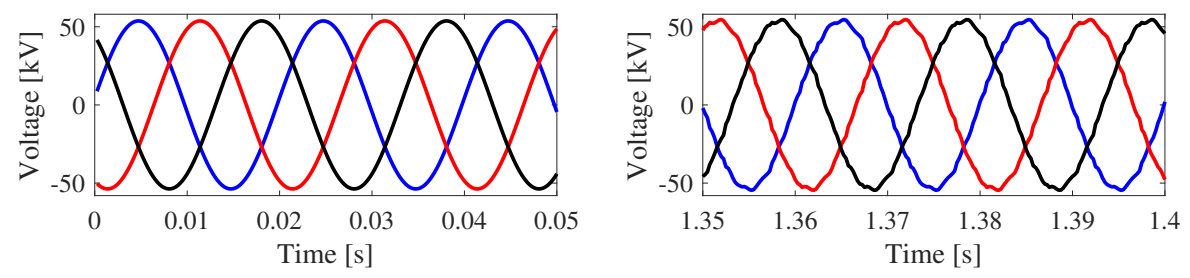

Figure 20. Three-phase voltages before (left) and after (right) the power ramp-up of DR-HVDC.

\section{Conclusions}

The operation of HVAC, VSC-HVDC, and DR-HVDC transmission systems integrating a large offshore wind farm with three different onshore power systems was investigated in this paper. A cascaded power and voltage control scheme was proposed for the DR-HVDC link's (onshore) converter to control the link's active power when the offshore AC voltage was within its normal operating range. A novel control scheme was developed for the VSC-HVDC link's offshore converter to enable the smooth transition between grid-following and grid-forming operation. The proposed controller could seamlessly switch to grid-forming operation and maintain the offshore frequency if the HVAC link was disconnected. This ensured that the operation of the offshore wind farm and the DR-HVDC link was not interrupted. The controller limited the current during faults and performed well when the offshore AC system was weak. The control scheme included a proposed PLL, which automatically unlocked from the offshore AC voltage if its frequency signal deviated beyond a given limit, e.g., when the HVAC link was disconnected, and returned such a signal to its nominal value. The simulation results verified the capability of the proposed controls for the DR-HVDC and VSC-HVDC transmission systems under different operating conditions.

Author Contributions: Conceptualization and methodology: A.B., O.S.-R., P.E.S., and N.A.C.; supervision: P.E.S., N.A.C., and V.A.; writing, review and editing: A.B., O.S.-R., N.A.C., and J.N.S.; data curation, formal analysis, investigation, project administration, software, validation, visualization, and writing, original draft: A.B.

Funding: This work has received funding from the European Union's Horizon 2020 research and innovation program under Grant Agreement No 691714.

Conflicts of Interest: The authors declare no conflict of interest. The funders had no role in the design of the study; in the collection, analyses, or interpretation of data; in the writing of the manuscript; nor in the decision to publish the results.

\section{References}

1. Raza, M.; Schönleber, K.; Gomis-Bellmunt, O. Droop Control Design of Multi-VSC Systems for Offshore Networks to Integrate Wind Energy. Energies 2016, 9, 826. [CrossRef]

2. CIGRÉ Working Group B4.55. HVDC Connection of Offshore Wind Power Plant; Technical brochure 619; CIGRÉ: Paris, France, 2015.

3. Blasco-Giménez, R.M.; Añó-Villalba, S.C.; Rodríguez-D’Derlée, J.; Morant-Anglada, F.; Bernal-Pérez, S.I. Distributed Voltage and Frequency Control of Offshore Wind Farms Connected With a Diode-Based HVdc Link. IEEE Trans. Power Electron. 2010, 25, 3095-3105. [CrossRef]

4. Blasco-Giménez, R.M.; Añó-Villalba, S.C.; Rodríguez-D’Derlée, J.; Bernal-Pérez, S.I.; Morant-Anglada, F. Diode-Based HVdc Link for the Connection of Large Offshore Wind Farms. IEEE Trans. Energy Convers. 2011, 26, 615-626. [CrossRef]

5. Bernal-Pérez, S.I.; Añó-Villalba, S.C.; Blasco-Giménez, R.M.; Rodríguez-D’Derlée, J. Efficiency and Fault Ride-Through Performance of a Diode-Rectifier- and VSC-Inverter-Based HVDC Link for Offshore Wind Farms. IEEE Trans. Ind. Electron. 2013, 60, 2401-2409. [CrossRef]

6. Christ, T.; Seman, S.; Zurowski, R. Investigation of DC Converter Nonlinear Interaction with Offshore Wind Power Park System. In Proceedings of the 2015 EWEA Offshore Conference, Copenhagen, Denmark, 10-12 March 2015. 
7. Menke, P.; Zurowski, R.; Christ, T.; Seman, S.; Giering, G.; Hammer, T.; Zink, W.; Hacker, F.; Imamovic, D.; Thisted, J.; et al. 2nd Generation DC Grid Access for Large Scale Offshore Wind Farms. In Proceedings of the 14th Wind Integration Workshop, Brussels, Belgium, 20-22 October 2015.

8. Yu, L.; Li, R.; Xu, L. Distributed PLL-Based Control of Offshore Wind Turbines Connected with Diode-Rectifier-Based HVDC Systems. IEEE Trans. Power Deliv. 2018, 33, 1328-1336. [CrossRef]

9. Saborío-Romano, O.; Bidadfar, A.; Göksu, Ö.; Cutululis, N.A. Frequency Support from OWPPs connected to HVDC via Diode Rectifiers. In Proceedings of the 16th Wind Integration Workshop, Berlin, Germany, 25-27 October 2017.

10. Saborío-Romano, O.; Bidadfar, A.; Sakamuri, J.N.; Göksu, Ö.; Cutululis, N.A. Primary Frequency Response from Offshore Wind Farms Connected to HVdc via Diode Rectifiers. In Proceedings of the 13th IEEE PES PowerTech Conference, Milano, Italy, 23-27 June 2019.

11. De Decker, J.; Kreutzkamp, P.; Woyte, A.; Dierckxsens, C. The Impact of Large-Scale Offshore Electricity Transmission: The European Project OffshoreGrid. In Proceedings of the 2012 9th International Conference on the European Energy Market, Florence, Italy, 10-12 May 2012; pp. 1-8.

12. Hoffmann, M.; Rathke, C.; Menze, A.; Hemdan, N.G.A.; Kurrat, M. Parallel Operation of HVDC DRU and VSC Converters for Offshore Wind Farm Connection: Technical and Economic Feasibility. In Proceedings of the 15th IET International Conference on AC and DC Power Transmission (ACDC 2019), Coventry, UK, 5-7 February 2019; pp. 1-6. [CrossRef]

13. Yu, L.; Li, R.; Xu, L. Hierarchical control of offshore wind farm connected by parallel diode-rectifier-based HVDC and HVAC links. IET Renew. Power Gener. 2019, 13, 1493-1502. [CrossRef]

14. PROMOTioN. Deliverable 2.3: Report on Simulation Results and Benchmark; Project deliverable; EU: Brussels, Belgium, 2019.

15. Trinh, N.; Zeller, M.; Wuerflinger, K.; Erlich, I. Generic Model of MMC-VSC-HVDC for Interaction Study With AC Power System. IEEE Trans. Power Syst. 2016, 31, 27-34. [CrossRef]

16. Muljadi, E.; Pasupulati, S.; Ellis, A.; Kosterov, D. Method of Equivalencing for a Large Wind Power Plant with Multiple Turbine Representation. In Proceedings of the IEEE PES 2008 General Meeting, Pittsburgh, PA, USA, 20-24 July 2008.

17. Kazmierkowski, M.P.; Malesani, L. Current Control techniques for Three-Phase Voltage-Source PWM Converters: A survey. IEEE Trans. Ind. Electron. 1998, 45, 691-703. [CrossRef]

18. Ooi, B.T.; Wang, X. Voltage Angle Lock Loop Control of the Boosted Type PWM Converter for HVDC Application. IEEE Trans. Power Electron. 1990, 5, 229-235. [CrossRef]

19. Joos, G.; Morán, L.; Ziogas, P. Performance Analysis of a PWM Inverter VAR Compensator. IEEE Trans. Power Electron. 1991, 6, 380-391. [CrossRef]

20. Zhang, L.; Harnefors, L.; Nee, H.P. Power-Synchronization Control of Grid-Connected Voltage-Source Converters. IEEE Trans. Power Syst. 2010, 25, 809-820. [CrossRef]

21. Bidadfar, A.; Nee, H.P.; Zhang, L.; Harnefors, L.; Namayantavana, S.; Abedi, M.; Karrari, M.; Gharehpetian, G.B. Power system stability analysis using feedback control system modeling including HVDC transmission links. IEEE Trans. Power Syst. 2015, 31, 116-124. [CrossRef]

(C) 2019 by the authors. Licensee MDPI, Basel, Switzerland. This article is an open access article distributed under the terms and conditions of the Creative Commons Attribution (CC BY) license (http:/ / creativecommons.org/licenses/by/4.0/). 